\title{
1 Dual-Element Isotope Analysis of Desphenylchloridazon to Investigate its 2 Environmental Fate in a Systematic Field Study - A Long-Term Lysimeter 3 Experiment
}

\author{
4 Aileen Melsbach ${ }^{a, \nabla, \S}$, Clara Torrentób ${ }^{b, \nabla}{ }^{\dagger}$, Violaine Ponsin ${ }^{b, q}$, Jakov Bolotinc, Laurence Lachat ${ }^{d}$, Volker \\ 5 Prasuhn ${ }^{\mathrm{e}}$, Thomas B. Hofstetter ${ }^{\mathrm{c}}$, Daniel Hunkeler ${ }^{\mathrm{b}}$, Martin Elsner ${ }^{\mathrm{a}, \mathrm{f}, *}$ \\ $6 \quad$ aHelmholtz Zentrum München, Institute of Groundwater Ecology, 85764 Neuherberg, Germany \\ $7{ }^{b}$ Centre for Hydrogeology and Geothermics (CHYN), University of Neuchâtel, 2000 Neuchâtel, Switzerland \\ 8 'Eawag, Swiss Federal Institute of Aquatic Science and Technology, 8600 Dübendorf, Switzerland and Institute of \\ 9 Biogeochemistry and Pollutant Dynamics, ETH Zürich, CH-8092 Zürich, Switzerland \\ 10 dNeuchâtel Platform of Analytical Chemistry (NPAC), University of Neuchâtel, 2000 Neuchâtel, Switzerland \\ 11 eAgroscope, Research Division, Agroecology and Environment, 8046 Zürich, Switzerland \\ 12 fTechnical University of Munich, Chair of Analytical Chemistry and Water Chemistry, 81377 Munich, Germany
}

14 Abstract

15 Desphenylchloridazon (DPC), the main metabolite of the herbicide chloridazon (CLZ), is more water 16 soluble and persistent than CLZ and frequently detected in water bodies. When assessing DPC 17 transformation in the environment, results can be non-conclusive if based on concentration analysis alone, because estimates may be confounded by simultaneous DPC formation from CLZ. This study 19 investigated the fate of DPC by combining concentration-based methods with compound-specific $\mathrm{C}$ and $20 \mathrm{~N}$ stable isotope analysis (CSIA). Additionally, DPC formation and transformation processes were 21 experimentally deconvolved in a dedicated lysimeter study considering three scenarios. First, surface 22 application of DPC enabled studying its degradation in the absence of CLZ. Here, CSIA provided evidence 23 of two distinct DPC transformation processes: one shows significant changes only in ${ }^{13} \mathrm{C} /{ }^{12} \mathrm{C}$, whereas the 24 other involves changes in both ${ }^{13} \mathrm{C} /{ }^{12} \mathrm{C}$ and ${ }^{15} \mathrm{~N} /{ }^{14} \mathrm{~N}$ isotope ratios. Second, surface application of CLZ 25 mimicked a realistic field scenario showing that during DPC formation, ${ }^{13} \mathrm{C} /{ }^{12} \mathrm{C}$ ratios of DPC were depleted 26 in ${ }^{13} \mathrm{C}$ relative to $\mathrm{CLZ}$, while ${ }^{15} \mathrm{~N} /{ }^{14} \mathrm{~N}$ ratios remained constant. Finally, CLZ depth injection simulated 27 preferential flow and demonstrated the importance of the topsoil for retaining DPC. The combination of 28 the lysimeter study with CSIA enabled insights into DPC transformation in the field that are superior to 29 studies of concentration trends. 


\section{Introduction}

32 Groundwater is one of the most important drinking water resources ${ }^{1}$ and, therefore, constantly screened

33 for contaminants ${ }^{2-5}$. Due to their extensive application in agriculture, pesticides and their metabolites ${ }^{6}$ are

34 commonly detected in ground and surface water. A prominent example is desphenylchloridazon (DPC),

35 the main metabolite of the herbicide chloridazon (CLZ). CLZ is a selective systemic herbicide that is used to control broad-leaved weeds in the agricultural production of swiss chard, red beet and sugar beet ${ }^{6-11}$.

37 The metabolite DPC is a compound of concern as it is continuously formed from CLZ. The continuous input of newly formed DPC makes it challenging to evaluate its environmental transformation from concentration data over time. Detection of DPC has increasingly been reported exceeding concentrations of $10 \mu \mathrm{g} / \mathrm{L}$ in natural water bodies ${ }^{6,11-14}$. DPC can be transported into ground and surface water by precipitation events as it is water-soluble $(490 \mathrm{mg} / \mathrm{L})$, and has a lower tendency to bind to the soil (Freundlich constant $\mathrm{K}_{\text {foc }}$ of $50 \mathrm{~mL} / \mathrm{g}$ ) than CLZ (K $\mathrm{K}_{\text {foc }}$ of $\left.199 \mathrm{~mL} / \mathrm{g}\right)$. Additionally, DPC has a high leaching potential, which is indicated by the groundwater ubiquity score (GUS) of 5.5, a parameter used to evaluate pesticides for their potential to seep into the groundwater $9,15,16$. Thus, there is great interest in the question whether DPC can be subject to further transformation. The fate of DPC, however, is not well understood yet ${ }^{2,17,18}$. It is known that DPC is a persistent and polar compound. In soil, it can be further transformed into methyldesphenylchloridazon (MDPC, Figure S1) $)^{10,12,19,20}$. Whether there is a wider range of degradation pathways, remains unclear.

Current attempts to quantify degradation of organic micropollutants are often based on metabolite-toparent-compound ratios. This is an analytical approach based on concentration measurements. It is advantageous to quantify degradation even at low concentration ranges, and is simple to use ${ }^{21}$. However, in case of DPC, which may be simultaneously formed while undergoing further transformation (Figure S1), metabolite-to-parent ratios can lead to erroneous interpretations ${ }^{22}$. An additional confounding factor is a different drainage-dependent re-mobilization of the parent compound and the metabolite due to differences in their mobility. Thus, concentrations may fluctuate in a non-trivial manner making it difficult, if not impossible, to inform about how much of the DPC has been transformed. Consequently, a complementary method is needed to detect transformation if metabolite analysis alone is not conclusive. 
and transformation of organic contaminants ${ }^{23-26}$. While CSIA of polar micropollutants has rarely been performed at field scales ${ }^{26}$, analytical methods for the analysis of carbon $\left({ }^{13} \mathrm{C} /{ }^{12} \mathrm{C}\right)$ and nitrogen $\left({ }^{15} \mathrm{~N} /{ }^{14} \mathrm{~N}\right)$ isotope ratios of DPC have recently become available ${ }^{27}$. So far, isotope studies of DPC have been carried out neither in laboratory experiments nor in field applications, however. As illustrated in Figure S1, unique insight on the formation and subsequent transformation of DPC can be expected. On the one hand, ${ }^{13} \mathrm{C} /{ }^{12} \mathrm{C}$ and ${ }^{15} \mathrm{~N} /{ }^{14} \mathrm{~N}$ ratios of DPC are expected to show the isotopic signature of the pyridazinone ring in the precursor CLZ. When CLZ is transformed, its phenyl-ring is first oxidized and then cleaved off. Thus, any isotope effect-induced changes in ${ }^{13} \mathrm{C} /{ }^{12} \mathrm{C}$ and ${ }^{15} \mathrm{~N} /{ }^{14} \mathrm{~N}$ ratios will be manifested in the molecular average of CLZ and in the oxidized phenyl-part that is cleaved off. In contrast, none of the molecular positions of the pyridazinone-ring are involved in the reaction, meaning that only secondary kinetic isotope effects occur so that the isotope ratios within the pyridazinone-ring remain mainly unaffected when they end up in DPC (Figure S1). If, however, further transformation of DPC takes place, this process is expected to result in pronounced changes in isotope ratios in DPC, because now, carbon and nitrogen atoms are directly involved (primary isotope effect). This would lead to carbon and nitrogen isotope fractionation in DPC giving a strong indication of further DPC transformation ${ }^{28}$. CSIA of DPC, therefore, holds promise to identify both processes, formation of DPC from CLZ, as well as independent further transformation of DPC. According to the current mechanistic picture, DPC is only formed from CLZ and transformed through Nmethylation $^{19,20,29}$. Thus, the combined analysis of carbon and nitrogen isotope ratios of DPC may offer new insights into its fate in soil leachate.

Evidence from CSIA may be inconclusive, however, if physical processes (e.g., multiple sorptiondesorption steps, dissolution from non-aqueous phase, volatilization/diffusion, dispersion) or the heterogeneity of the system, the soil in this case, affect degradation-induced changes in isotope ratios. For example, a freshly dissolved compound, which has not been transformed yet, can mix with water containing the contaminant that has already undergone varying degrees of degradation and thus isotope fractionation $^{30-32}$. Consequently, the transformation-induced isotope ratios in the degraded fraction might not be discernible any longer ${ }^{33,}{ }^{34}$. When applying CSIA to a field site either for the interpretation of a compound's environmental fate or to monitor the success of remediation processes, it is therefore suggested to combine it with complementary approaches in order to obtain as many lines of evidence as possible $^{30,35,36}$.

Thus, the aim of this study was to explore different complementary and innovative approaches for assessing the environmental long-term fate of DPC in drainage water after agricultural application over a 
period of 3 years. To that end, we combined concentration measurements with the analysis of carbon and nitrogen isotope ratios in a comprehensive and systematic study in a well-characterized model lysimeter system. This lysimeter system mimics pesticides fate in natural soil environment under high control over environmental and hydrological factors (i.e. soil type and humidity, precipitation levels, temperature, evapotranspiration, etc.). In order to separate the relevant transport and transformation processes, these complementary approaches were integrated into a dedicated experimental design where CLZ and DPC were applied in three different scenarios (Figure S2): (i) DPC was applied to the lysimeter directly, without the presence of $C L Z$, to investigate whether further DPC transformation is observable in drainage water and whether this transformation is detectable from analyzing carbon and nitrogen isotope signatures of DPC when interfering simultaneous formation of DPC can be excluded. (ii) The concurrent formation of DPC from CLZ and potential DPC transformation were evaluated through surface application of CLZ to the lysimeters. (iii) To simulate the preferential flow and to study whether DPC formation and transformation is also occurring below the top soil, CLZ was injected below the root zone. For each scenario, these complementary approaches were tested with two different soil types through a replication of the lysimeter studies with moraine and gravel soil, respectively.

\section{Experimental / Methods}

Experimental Set-up of Lysimeter Experiments. For this study, the lysimeter facility from Agroscope was used, located in Zurich-Reckenholz, Switzerland. The facility itself and the characteristics of the lysimeters are described in detail by Torrentó et al. ${ }^{37}$. Briefly, the site consisted of 12 gravitation lysimeters (L) (3.14$\mathrm{m}^{2}$ surface area, $2.5 \mathrm{~m}$ depth, approximately $14000 \mathrm{~kg}$ of soil in each) filled with two soil types

112 (gravel/moraine). Both soil types consisted of repacked Cambisol. Cambisols, widely and intensively used as agricultural land, are among the most extensive soil types on earth, extending over about $11 \%$ of the global land surface ${ }^{38}$. The soils used in this study differed in the B horizon and the draining properties of the parent material, and thus they were expected to show a different extent of preferential flow ${ }^{37}$. Gravel soil was represented by well-drained sandy loamy Cambisol (L1-L6), while moraine soil consisted of a poorly drained loamy Cambisol (L7-L12) (Table S1). Six of these lysimeters were used for this study (three of each soil type). The lysimeters were planted in 2014 with corn (Zea mays L.) followed by sugar beet 
121

122

123

124

125

126

127

128

129

130

131

132

133

134

135

136

137

138

139

140

141

142

143

144

145

146

147

148

149

150

151

152

on the surface of two lysimeters (L4 and L8) simulating the scenario of pesticide application at the threeto four-leaf stage in the field ${ }^{10}$. To simulate preferential transport through topsoil, two additional lysimeters were used (L6 and L7), where $2.0 \mathrm{~g}$ of CLZ were injected in each lysimeter at a depth of $40 \mathrm{~cm}$ at eleven injection points uniformly distributed over the area of each lysimeter by using a metal rod connected to a gear pump through a Teflon tube. Additionally, $3.2 \mathrm{~kg} / \mathrm{ha}$ (1.0 g/lysimeter) DPC was applied on the surface of two lysimeters (L1 and L12). In addition to CLZ or DPC, the following tracers were applied at the same time as the pesticides: uranine $(1.3 \mathrm{~kg} / \mathrm{ha})$ and $\mathrm{NaBr}(500 \mathrm{~kg} / \mathrm{ha})$ to lysimeters $\mathrm{L} 1$ and $\mathrm{L} 12$, uranine $(1.3 \mathrm{~kg} / \mathrm{ha}$ ) to lysimeters $\mathrm{L} 4$ and $\mathrm{L} 8$, and uranine $(0.4 \mathrm{~g}$ injected in each lysimeter) to lysimeters $\mathrm{L} 6$ and L7. Bromide was used as conservative tracer and uranine ( $\mathrm{K}_{\mathrm{foc}}$ of $\left.120 \mathrm{~mL} / \mathrm{g}\right)$ as a marker for preferential leaching shortly after pesticide application ${ }^{37}$. A detailed set-up is shown in the Supporting Information (sections II.2 and II.3). Details about application methods can be found in Torrentó et al. ${ }^{37}$. All lysimeters were irrigated artificially and the seepage water was collected for analysis over a time period of 3 years (Table S2).

Concentration Measurements of CLZ, DPC and MDPC. For concentration measurements of CLZ, DPC and MDPC, an Ultimate ${ }^{\circledR} 3000$ RS high-pressure liquid chromatography (HPLC) (Dionex, Thermo Fisher Scientific, Waltham, MA, USA) coupled to a 4000-hybrid triple quadrupole-linear ion trap mass

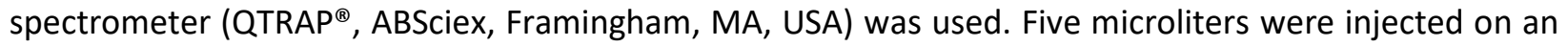
Acquity UPLC BEH Shield RP18 column (100 $\times 2.1 \mathrm{~mm}, 1.7 \mu \mathrm{m}$, Waters, Milford, MA, USA) maintained at $25^{\circ} \mathrm{C}$. The separation was performed at a flow rate of $0.4 \mathrm{~mL} / \mathrm{min}$ using a binary mobile phase system consisting of $0.05 \%$ formic acid in water (mobile phase A) and $0.05 \%$ formic acid in acetonitrile (mobile phase B) according to the following gradient program: 5-15\% phase B in $2 \mathrm{~min}, 15-100 \%$ phase B in 4 min, holding at $100 \%$ phase $\mathrm{B}$ for $2 \mathrm{~min}$, and re-equilibration at $2 \%$ phase $\mathrm{B}$ for $6 \mathrm{~min}$. Detection was performed in electrospray positive ionization (ESI+) using the multiple reaction monitoring (MRM) mode by monitoring both a quantifier $(\mathrm{Q})$ and a qualifier $(\mathrm{q})$ transition ion for each compound. Precursor and fragment ions (m/z) were 222.1 and 104.0 (Q) or 77.0 (q) for CLZ, 146.0 and $117.0(\mathrm{Q})$ or 66.0 (q) for DPC, 160.0 and 117.0 (Q) or 88.0 (q) for MDPC, and 227.0 and 108.0 (Q) or 81.0 (q) for CLZ- $\mathrm{d}_{5}$, respectively (Table S3). Quantification was performed using standard curves calculated from standard solutions of CLZ, DPC and MDPC at $0.25,0.5,1,3,5$ and $10 \mathrm{ng} / \mathrm{mL}$, each containing deuterated CLZ- $\mathrm{d}_{5}$ as internal standard at a constant concentration of $2 \mathrm{ng} / \mathrm{mL}$. The limits of quantification were $0.05 \mu \mathrm{g} / \mathrm{L}$ for CLZ, $0.4 \mu \mathrm{g} / \mathrm{L}$ for DPC and $0.1 \mu \mathrm{g} / \mathrm{L}$ for M-DPC. For those drainage water samples with CLZ, DPC and MDPC concentrations lower than $0.2 \mu \mathrm{g} / \mathrm{L}$, solid-phase extraction (SPE) of 20-mL samples was performed using $6 \mathrm{~mL}$ cartridges packed with $0.2 \mathrm{~g}$ of Bakerbond SDB-1 sorbent and $0.2 \mathrm{~g}$ of Sepra ZT sorbent, as described by Torrentó et 
al. ${ }^{39}$. After SPE, the extracts were analyzed by UHPLC-QTOF-MS. The method is briefly described in the 154 Supporting Information (II.5.).

155 156

Large Volume Solid-Phase Extraction. For isotope analysis, all lysimeter samples were filtered through 0.7- $\mu \mathrm{m}$ glass fiber filters and were concentrated by SPE using the method described in Torrentó et al. ${ }^{39}$, as detailed in the Supporting Information (II.6.).

\section{Elemental Analyzer-Isotope Ratio Mass Spectrometry Measurement for Determination of Reference}

Values. Carbon and nitrogen isotope reference values of our in-house standards of CLZ, DPC and MDPC were determined by elemental analysis - isotope ratio mass spectrometry (EA-IRMS) according to the method of Meyer et al. ${ }^{40}$. The system consisted of an EuroEA (Euro Vector, Milano, Italy) coupled with a Finnigan MAT 253 IRMS via a FinniganTM ConFlow III interface (Thermo Fisher Scientific, Bremen, Germany). For calibration, USG 40, USG 41 (L-glutamic acid) and IAEA 600 (caffeine), supplied by the International Atomic Agency (IAEA), were used as organic reference materials.

Carbon $\left(\delta^{13} \mathrm{C}\right)$ and nitrogen $\left(\delta^{15} \mathrm{~N}\right)$ isotope signatures are usually expressed using the Delta notation in per mille as described in equation 1 and 2 . There, the isotope ratios $\left({ }^{13} \mathrm{C} /{ }^{12} \mathrm{C}\right.$ sample and $\left.{ }^{15} \mathrm{~N} /{ }^{14} \mathrm{~N}_{\text {sample }}\right)$ are stated relative to the international references PeeDee Belemnite (V-PDB) for carbon and air for nitrogen.

$$
\delta^{13} \mathrm{C}=\frac{{ }^{13} \mathrm{C} /{ }^{12} \mathrm{C}_{\text {Sample }}{ }^{-13} \mathrm{C} /{ }^{12} \mathrm{C}_{\text {Reference }}}{{ }^{13} \mathrm{C} /{ }^{12} \mathrm{C}_{\text {Reference }}}
$$

$$
\delta{ }^{15} \mathrm{~N}=\frac{{ }^{15} \mathrm{~N} /{ }^{14} \mathrm{~N}_{\text {Sample }}{ }^{15} \mathrm{~N} /{ }^{14} \mathrm{~N}_{\text {Reference }}}{{ }^{15} \mathrm{~N} /{ }^{14} \mathrm{~N}_{\text {Reference }}}
$$

Carbon Isotope Analysis of DPC by LC- IRMS. For carbon isotope analysis of DPC we applied the method of Melsbach et al. ${ }^{27}$. Briefly, 10 to $100 \mu \mathrm{L}$ of SPE extracts reconstituted in ultrapure water were injected into an LC-IRMS Dionex system consisting of an Ultimate 3000 HPLC pump and an Ultimate 3000 autosampler (Thermo Fisher Scientific) coupled via an LC-Isolink interface with a Delta V Advantage IRMS (Thermo Fisher Scientific). Chromatography was accomplished using a Sentry guard column (3 $\mu \mathrm{m}$, $20 \mathrm{~mm}$ ) and an Atlantis T3 column ( $3 \mu \mathrm{m}, 100 \mathrm{~mm}$, Waters) at a flow rate of $500 \mu \mathrm{L} / \mathrm{min}$. Phosphoric acid at $\mathrm{pH} 2$ was chosen as mobile phase. The method was run isocratically at room temperature. The analytes were converted by wet oxidation at a temperature of $99.9^{\circ} \mathrm{C}$ after the separation unit. Thereto, $90 \mathrm{~g} / \mathrm{L}$ 
$\mathrm{Na}_{2} \mathrm{~S}_{2} \mathrm{O}_{8}$ and phosphoric acid $\left(1.5 \mathrm{M} \mathrm{H}_{3} \mathrm{PO}_{4}\right)$ were introduced at a flow rate of $30 \mu \mathrm{L} / \mathrm{min}$. The vacuum inside the IRMS was $2 \times 10^{-6}$ mbar. Its ion source was set to an accelerating voltage of $3 \mathrm{kV}$ and an electron ionization energy of $124 \mathrm{eV}$. The isotope ratios were calibrated using our laboratory monitoring gas $\left(\mathrm{CO}_{2}\right)$, which had previously been calibrated against the international standard RM8563 $\left(\mathrm{CO}_{2}\right)$, supplied by the IAEA.

Derivatization of DPC for Nitrogen Isotope Analysis. Nitrogen isotope analysis was conducted using the derivatization procedure proposed by Melsbach et al. ${ }^{27}$. Briefly, DPC was methylated to MDPC by adding an excess of greater than $160 \mathrm{n}_{\text {analyte }} / \mathrm{n}_{\text {TMSD }}(140 \mu \mathrm{L}$ of a $2 \mathrm{M}$ TMSD solution) into a vial containing a standard or a SPE extract reconstituted in $1 \mathrm{~mL}$ methanol. The vial was crimped tightly before putting it into a $70^{\circ} \mathrm{C}$ water bath for $2 \mathrm{~h}$. For samples from lysimeters with CLZ depth injection, the volume of the $2 \mathrm{M}$ TMSD solution added to the reconstituted SPE extracts was increased to $200 \mu \mathrm{L}$ to ensure complete derivatization, as concentrations of DPC were up to an order of a magnitude higher compared to the other lysimeter samples. Afterwards, the solvent was evaporated to dryness. The sample was then reconstituted in $50 \mu \mathrm{L}$ acetone.

Separation of Drainage Sample Fractions for Analysis of DPC and MDPC. For drainage water samples from the lysimeters where CLZ was applied on the surface and for which the ratio of DPC to naturally formed MDPC was greater than $10 \%$, preparative HPLC was used prior to derivatization to isolate this naturally formed MDPC and thus to avoid interferences in the isotopic signature of DPC when subjected to methylation in the derivatization procedure. The method is briefly summarized in the Supporting Information (II.7.) ${ }^{27}$. Additionally, both DPC and MDPC fractions were used for $\delta^{15} \mathrm{~N}$ isotope analysis when possible. For samples with an MDPC to DPC ratio $<10 \%$, no preparative HPLC method was applied prior to derivatization, as the influence of the isotope ratio of MDPC on the isotope ratio of derivatized DPC is negligible and lies within the measurement error for nitrogen CSIA ( $\pm 1 \%$ ) of the developed ${ }^{15} \mathrm{~N}$ GC-IRMS method $^{27}$.

Nitrogen Isotope Analysis of DPC and MDPC. The method is described by Melsbach et al. ${ }^{27}$ Briefly, a TRACE GC Ultra gas chromatograph (Thermo Fisher Scientific, Milan, Italy) coupled with a Finnigan MAT 253 IRMS (Thermo Fisher Scentific, Bremen, Germany) was used. A Finnigan Combustion III interface (Thermo Fisher Scientific) connected both instruments. The analytes were combusted at a temperature of $1030^{\circ} \mathrm{C}$ with a NiO tube/CuO-NiO reactor (Thermo Fisher Scientific). The gas chromatograph contained a DB-1701 column (30 m ×0.25 mm × $1 \mu \mathrm{m}$, J\&W Scientific, Santa Clara, CA). Helium (grade 5.0) at a flow rate of $1.4 \mathrm{~mL} / \mathrm{min}$ was used as carrier gas. Injection was carried out with a GC Pal autosampler (CTC, 
Zwingen, Switzerland). A sample volume ranging between 1 and $3 \mu \mathrm{L}$ was injected into a splitless liner (Thermo Fischer Scientific, Australia) at a temperature of $250^{\circ} \mathrm{C}$. The $\mathrm{GC}$ oven was programmed to start at a temperature of $100^{\circ} \mathrm{C}$ (held for $1 \mathrm{~min}$ ), ramped with $25^{\circ} \mathrm{C} / \mathrm{min}$ to $240{ }^{\circ} \mathrm{C}$, and with $10^{\circ} \mathrm{C} / \mathrm{min}$ to $280^{\circ} \mathrm{C}$ (held for $5 \mathrm{~min}$ ). The isotope ratios were calibrated using our laboratory monitoring gas $\left(\mathrm{N}_{2}\right)$, which had previously been calibrated against the international standard NSVEC $\left(\mathrm{N}_{2}\right)$, supplied by the IAEA.

Correction Procedure for Isotope Analysis. Analogous to the correction procedure described by Melsbach et al. ${ }^{27}$, all samples and standards were measured in triplicate and their isotope ratios are reported as the arithmetic means with their respective estimated standard deviations $( \pm \sigma)$. In addition to the calibration of the measurement gas, samples are bracketed within the sequences by in-house standards of DPC and MDPC, whose isotopic signature had been determined with EA-IRMS (Table S4). Here, the principle of identical treatment by Werner and Brand ${ }^{41}$ was applied to correct for trueness by identifying drifts and off-sets, caused by different combustion efficiency. $\delta^{15} \mathrm{~N}$ correction was performed using MDPC synthesized by LGC Standards GmbH, while an authentic DPC standard was used for $\delta^{13} \mathrm{C}$ correction of the LC-IRMS method.

Concentration Measurement of CLZ and DPC from Soil Samples. CLZ and DPC residues were measured within the first soil layers $(0$ to $10 \mathrm{~cm}$ ) approximately one year after herbicide/metabolite application. To obtain a representative and homogenous sample, subsamples for soil analysis were collected in quadruplets and combined afterwards. The total amount was at least $100 \mathrm{~g}$ soil per sample. Sample extraction and analysis were carried out by Eurofins Sofia GmbH using LC-MS/MS.

Statistical Analyses. Pearson correlation analysis and one-way analyses of variance (ANOVA) tests were performed to identify patterns and to measure the statistical significance of the relationship between variables. ANOVA tests were performed to assess the differences between soil types and pesticide application methods regarding total accumulated drainage, total DPC mass leached, maximum change of carbon and nitrogen isotope signatures 900 days after pesticide application/injection. Separate Pearson linear correlations were performed to evaluate the relationship between irrigation and drainage, between soil humidity and drainage, between drainage and DPC mass leached, and between evapotranspiration and DPC mass leached. All tests were performed using the statistical package Minitab 13.31 (Minitab Inc., State College, PA). All statistical differences were set to the $\alpha=0.05$ significance level $(p \leq 0.05)$.

\section{Results and Discussion}


Water Dynamics. Total accumulated drainage 900 days after CLZ or DPC application/injection was between 488 to $656 \mathrm{~mm}$ for gravel soil and between 337 and $502 \mathrm{~mm}$ for moraine soil. In relation to the water input, drainage represented $25-39 \%$ and $18-27 \%$ of the total irrigation, respectively. Increased drainage coincided with periods of high irrigation intensity and high soil water content. A significant positive correlation (Pearson's correlation coefficient $-r-$ from 0.30 to $0.49, p<0.0001$ ) between intensity of daily irrigation and daily drainage was observed for the six lysimeters. As detailed by Torrentó et al. ${ }^{37}$, who used the same lysimeters to assess the fate of the herbicide atrazine and its metabolites, soil humidity data revealed that large irrigation events resulted in a greater contribution of preferential flow to drainage, and that this effect was more significant for the moraine than for the gravel soil. A statistically significant $(p<0.05)$ correlation was observed between soil humidity and drainage for both gravel and moraine soil at all depths where capacitance sensors were installed (at 16, 36, 56, 76, and $96 \mathrm{~cm}$ for moraine soil and at 11,51 , and $71 \mathrm{~cm}$ for gravel soil) ${ }^{37}$. This correlation was stronger for moraine $(\mathrm{r}$ between 0.15 and 0.22, except for one depth with $r=0.08$ ) than for gravel soil ( $r$ between 0.06 and 0.16 ), and is in accordance with the fact that fluctuations in the soil water content were smaller for the latter, especially at greater depths ${ }^{37}$. The total accumulated drainage after 900 days was influenced by the application method (higher drainage for depth injection, $p=0.331$ ) and by the soil type (higher for gravel soil, $p=0.426)$. Large amounts of drainage from the gravel soil are probably a consequence of the higher water permeability and low water content at field capacity of this soil ${ }^{37}$.

256 The average monthly and annual irrigation, drainage, and evapotranspiration values for the lysimeters used in this study are shown in Table S5. Annual evapotranspiration, estimated by the water balance computation as explained by Torrentó et al. ${ }^{37}$, was for the four years of study (2014 to 2017) higher for moraine (315 to $633 \mathrm{~mm}$ ) than for gravel soil (266 to $585 \mathrm{~mm}$ ), although the effect was not statistically significant $(p=0.718)$. A significant effect $(p=0.002)$ on annual evapotranspiration was however observed for crop type: evapotranspiration was higher for sugar beet and corn than for broccoli, Chinese cabbage, lettuce and leek. The effects of soil type and pesticide application method on evapotranspiration 900 days after pesticide application were not statistically significant $(p=0.093$ and $p=0.579$, respectively). The influence of the cover vegetation on drainage and pesticides fate was not assessed, since no significant differences in the plants development were observed between lysimeters. For details, see Supporting Information section III.2.

267 Trends in Compound Concentrations after DPC Surface Application. Neither CLZ, nor DPC had ever been 268 
uniquely attributed to our experimental design. Through application of the metabolite DPC to the surface

270 of the lysimeters, it was possible to investigate the fate of DPC separately, in the absence of CLZ and 271 without interference of constantly formed DPC. The breakthrough of DPC in the seepage water differed 272 between the soil types (Figure 1 b). In the lysimeter with moraine soil (L12), concentrations changed more 273 rapidly in relation with drainage events than for gravel soil (L1). For gravel soil (L1), DPC was detected in 274 the drainage water for the first time after 137 days, while it broke through only 15 days after application 275 in moraine soil (L12). In these lysimeters, a positive correlation was observed between drainage and DPC mass leached, being more significant for gravel $(r=0.36, p=0.029)$ than for moraine soil $(r=0.31, p=$ 277 0.113). The observed dependency of the drainage response, and the analytes' concentration therein, on 278 the irrigation agrees with Torrentó et al. ${ }^{37}$ for the fate of the herbicide atrazine and its metabolites in 279 these lysimeters. Table S6 summarizes the observed breakthrough parameters for each lysimeter. Two main DPC concentration peaks were detected in the drainage water of these two lysimeters after approximately 550 and 850 days (Figure 1e). They coincided with two intense irrigation events (November 2016 and September 2017, Table S2). In moraine soil (L12, 303 and $441 \mathrm{~mm}$ ), less accumulated drainage had occurred at peak concentration of DPC than in the gravel soil (L1, 458 and $852 \mathrm{~mm}$ ). Concentrations in the gravel soil were approximately one order of magnitude higher than in moraine soil. In contrast to our previous study ${ }^{37}$, no rapid breakthrough peak was observed shortly after application, neither for DPC nor for uranine (Figure S4). Bromide mass recovery curves (Figure S5) showed an asymmetric sigmoidal shape, which is characteristic for transport through a porous matrix with some retardation. Smoother trends for DPC compared to the tracers indicate retardation by sorption and/or attenuation by degradation. DPC leaching was therefore mainly driven by porous matrix flow, although intense irrigation events resulted in a greater contribution of preferential flow. This was observed mainly in moraine soil. For example, after 425 and 670 days, sharp increases in DPC concentrations were measured (Figure S4). 292 This might be a consequence of transport by preferential flow induced by intense irrigation events (July 293 2016 and March 2018, respectively, Table S2).

The transformation product of DPC, MDPC, was first detected after 256 days and 425 days for gravel and moraine soil, respectively. At the end of the monitoring period (950 days after DPC application), $6.0 \%$ of 297 (details about the calculation of analyte recovery can be found in the Supporting Information section II.9). 298 MDPC accounted for $0.55 \%$ and $0.06 \%$ of the applied DPC, respectively. One year after application, a DPC 299 residue of approximately $3 \%$ and $7 \%$ of the applied DPC was quantified within the first soil layers (0 to $30010 \mathrm{~cm}$ ) of gravel and moraine soil, respectively (Table S7). Thus, an incomplete mass balance was 
observed. Here, possible explanations might be: (i) sorption of DPC to lower soil layers within the root zone, where further sampling was not possible without disturbing the lysimeter, (ii) the uptake and metabolism of DPC by plants ${ }^{42,43}$, and (iii) the presence of DPC-fulvic acid complexes, as their functional groups can bind DPC. This has been demonstrated by Gatzweiler ${ }^{44}$, who conducted lysimeter experiments with ${ }^{14} \mathrm{C}$-labelled CLZ. Using thin-layer chromatography and analyzing the radioactivity, Gatzweiler ${ }^{44}$ detected DPC in fulvic acid fractions verifying the existence of these DPC-fulvic acid complexes. Nevertheless, the MDPC/DPC concentration ratio suggests that further DPC degradation to MDPC occurred in both soils, mainly after 425 days. (As both DPC and MDPC have a similar GUS leaching potential and show only minor differences in their mobility, no major retardation effect on the transport of either compound is expected so that the use of metabolite-to-parent compound ratios appears justified in this case) $)^{9}$. This further degradation agrees with the findings of Schuhmann et al. $^{42}$ and the environmental degradation pathway predicted by Roberts et al. $^{19}$. This demonstrates that transformation of DPC is occurring only slowly. For the moraine soil, a local maximum for the MDPC/DPC concentration ratio was reached after 750 days (Figure 1, L12e). To obtain additional insight into DPC transformation, we, therefore, evaluated the results from CSIA of the lysimeter experiment.

Insights into DPC Transformation by Isotope Analysis of DPC from Surface Application. Initially, the $\delta^{13} \mathrm{C}$ and $\delta^{15} \mathrm{~N}$ values of the leached DPC were close to the original isotope signature of the applied DPC (Figures 1, L1d and L12d). Over the course of the observation period carbon isotope signatures of DPC showed significant enrichment in ${ }^{13} \mathrm{C}\left(\Delta \delta^{13} \mathrm{C}_{\mathrm{DPC}}\right)$ of approximately $+4 \%$ in both soil types. The heavy irrigation event 672 days after DPC surface application (March 2017, Table S2) caused a new small DPC breakthrough peak, in which DPC isotope values returned to the original isotopic composition, most likely because new DPC was mobilized, which had not yet been subject to transformation. This effect was more significant in moraine soil, where a greater contribution of preferential flow in response to this heavy irrigation event was observed, resulting in a recovery of up to $20 \%$ of the total mass of DPC leached in the drainage water after the monitoring period. Additionally, significant changes of nitrogen isotope signatures $\left(\Delta \delta^{15} \mathrm{~N}_{\mathrm{DPC}}\right.$ ) of $+2 \%$ to $+3 \%$ o were observed - however, mainly in the gravel soil (L1). Furthermore, these shifts were observed at a later time point than the enrichment in ${ }^{13} \mathrm{C}$, approximately 450 days after application. The fact that during the first 450 days DPC was only becoming enriched in ${ }^{13} \mathrm{C}$, and then in both ${ }^{13} \mathrm{C}$ and ${ }^{15} \mathrm{~N}$, suggests that DPC was transformed by two distinct processes and that only the latter one starting after 450 days involved a reaction of a nitrogen atom. The transition between the two trends coincides with an increase in the MDPC/DPC concentration ratio (Figure 1, L1e). As there had never been any application of CLZ or DPC to these lysimeters, the carbon and nitrogen isotope values of 
333 DPC can be uniquely attributed to the substance applied in this study, and changes in these isotope 334 signatures are attributable to its further degradation. Interestingly, due to the high concentrations of 335 MDPC in the drainage water, it was possible to measure the $\delta^{15} \mathrm{~N}$ of formed MDPC after purification by 336 preparative HPLC (Tables S9 and S10). In both lysimeters, the $\delta^{15} \mathrm{~N}$ of MDPC was significantly more 337 negative (approximately by $4 \%$ ) compared to the $\delta^{15} \mathrm{~N}$ value of the DPC at that time (Figure $1 \mathrm{~d}$ ). Since 338 DPC contains three nitrogen atoms out of which only one is methylated, it can be estimated that the 339 methylation of DPC causes a nitrogen isotope effect of approximately $3 \times 4 \%$ \% $=+12 \%$ at the reactive 340 atom. Our data for the DPC surface application show an enrichment in ${ }^{13} \mathrm{C}$ and, to a lesser extent, in ${ }^{15} \mathrm{~N}$ 341 for DPC in both soils, which was significantly masked in the moraine soil due to the leaching of fresh DPC 342 after heavy irrigation events. Transformation extent can thus be underestimated. Here, transformation of 343 DPC may be easier to detect using the metabolite-to-parent concentration ratio, at least for the pathway 344 involving MDPC formation. On the other hand, using the metabolite-to-parent concentration ratio only to 345 investigate the transformation of DPC, the evidence of an additional transformation mechanism would 346 have remained undetected. Additionally, CSIA appears to be more robust as the integrated isotope signal, 347 which indicates degradation remains measurable, even if the metabolite might be subject to sorption or 348 further transformation. 
L1, gravel soil
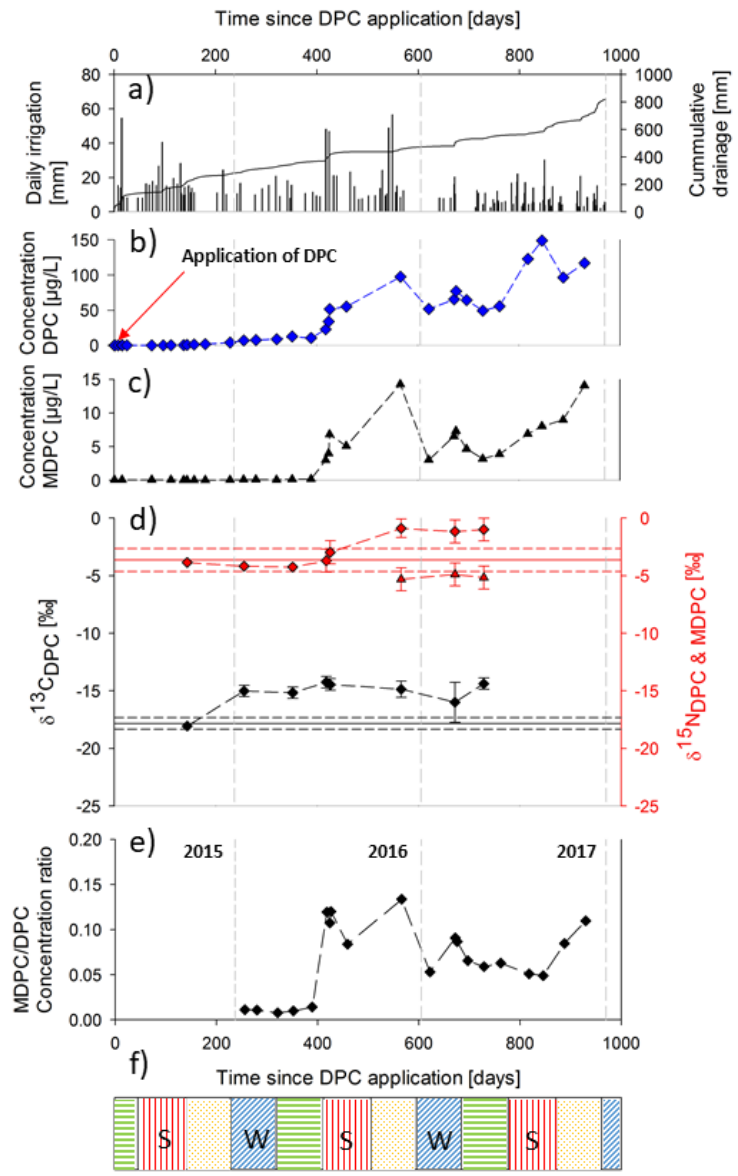

L12, moraine soil
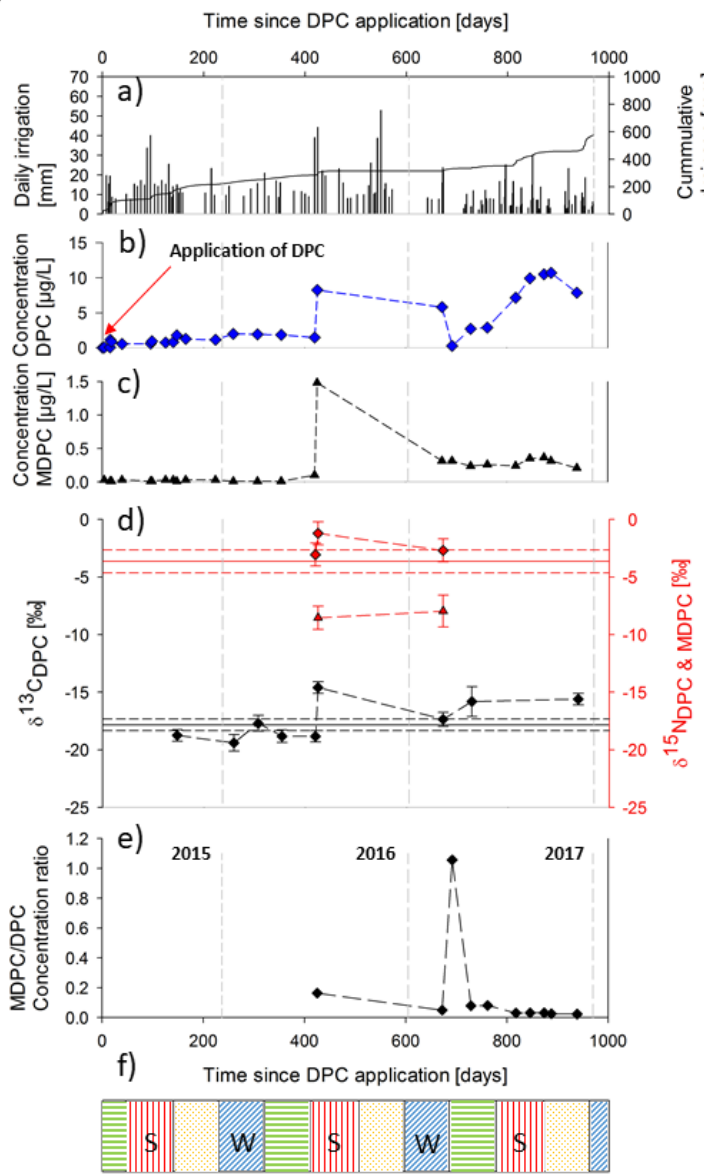

Figure 1. Lysimeters with DPC application on surface (a single application in May 2015): L1 in gravel soil (left panels) and L12 in moraine soil (right panels). a) Daily irrigation (black bars) and cumulative drainage (grey line); b)-c) Concentration of DPC (blue diamonds) and MDPC (black triangles), note that different scales are used for both soil types; d) Carbon (black diamonds) and nitrogen (red diamonds) isotope ratios of DPC and nitrogen isotope values of MDPC (petrol triangles), error bars show the associated uncertainties $( \pm 0.5 \%$ for carbon, $\pm 1.0 \%$ o for nitrogen isotope analysis; or when exceeding this uncertainty, standard deviations of triplicate measurements are given , EA isotope values of the applied DPC are shown as lines, whereas associated uncertainties $( \pm 0.5 \%$ for carbon, $\pm 1.0 \%$ for nitrogen isotope analysis) are shown as dashed lines in the corresponding color, respectively; e) metabolite-to-parent compound molar ratio of MDPC/DPC (black diamonds); f) season corresponding to the time since application - spring (green horizontal lines), summer (red vertical lines), autumn (yellow dots), winter (blue diagonal lines); the grey dashed lines repeated in each sub-figure represent the start of a new year.

CLZ Surface Application Mimicking A Realistic Field Scenario. For the surface application of CLZ (Figure 2, L4 and L8), the metabolites DPC and MDPC were detected in the seepage water 425 days after CLZ application, coinciding with a heavy irrigation event (July 2016, Table S2), while the applied parent 
compound remained below or close to the limit of detection of $0.05 \mu \mathrm{g} / \mathrm{L}$ during the time of monitoring (970 days). Analytes breakthrough curves and concentrations differed between the soil types. For uranine, a rapid breakthrough shortly after application was detected in moraine soil (Figure S4). During the monitoring period, the maximum uranine concentration was measured within the first day, after only 4 $\mathrm{mm}$ of accumulated drainage (Table S6), suggesting that it was mainly transported through preferential flow, bypassing large fractions of the soil matrix. Furthermore, a pronounced uranine peak tailing was observed, which is typical for preferential flow (Figure S4). Furthermore, the DPC mass recovery curves were significantly different for the two soils (Figure S5), giving further evidence of a greater contribution

372 of transport through preferential flow for moraine soil. This difference in soil type agrees with the results

373 of the lysimeters with surface application of DPC as well as well as with the findings for other compounds 374 described in Torrentó et al. ${ }^{37}$.

Approximately $0.5 \%$ and $0.13 \%$ of the applied CLZ was leached as DPC after 950 days in gravel and moraine soil, respectively. When analyzing the CLZ and DPC content in the upper soil, for none of the lysimeters a closed mass balance was obtained. While no CLZ was detected in the first soil layer (0 to $10 \mathrm{~cm}$ ) approximately 1 year after CLZ application to the lysimeter surface (consistent with Pestemer \& Malkomes ${ }^{45}$ ), DPC amounts corresponding to 5 to $9 \%$ of the applied CLZ were found (Table S7). CLZ and DPC are expected to be incorporated into maize plants based on the findings of Schuhmann et al. ${ }^{42}$ and Stephenson \& Ries ${ }^{43}$. In addition, Barra et $a l .{ }^{46}$ showed that during the first 90 days after CLZ application, CLZ dissipation was mainly due to volatilization and degradation, whereas later on, when CLZ was already in the subsurface, its disappearance from soil occurred mainly due to degradation. Higher DPC/CLZ concentration values were measured in the drainage water of the gravel soil compared to moraine soil. These results suggest that either DPC leached more rapidly through the soil matrix in the gravel soil because of higher permeability. Or, alternatively, the extent of CLZ degradation was higher for the gravel soil compared to moraine soil, as there is a greater contribution of preferential flow in moraine soil, which bypasses the top layer where degradation is mostly expected to take place. When preferential flow occurs, pesticides bypass large fractions of the soil matrix, reducing the degradation and sorption potential, as the topsoil is microbiologically more active and with higher organic matter content. CSIA results provide additional insights about these two hypotheses (see below). Concentration ratios and isotope results point to a higher extent of CLZ degradation in gravel than in moraine soil. Nevertheless, some metaboliteto-parent ratio values may be underestimated, because CLZ was below the limit of detection and, therefore, CLZ concentrations corresponding to the detection limit were chosen for calculation, resulting in a minimum estimated ratio in that case. 
L4, gravel soil
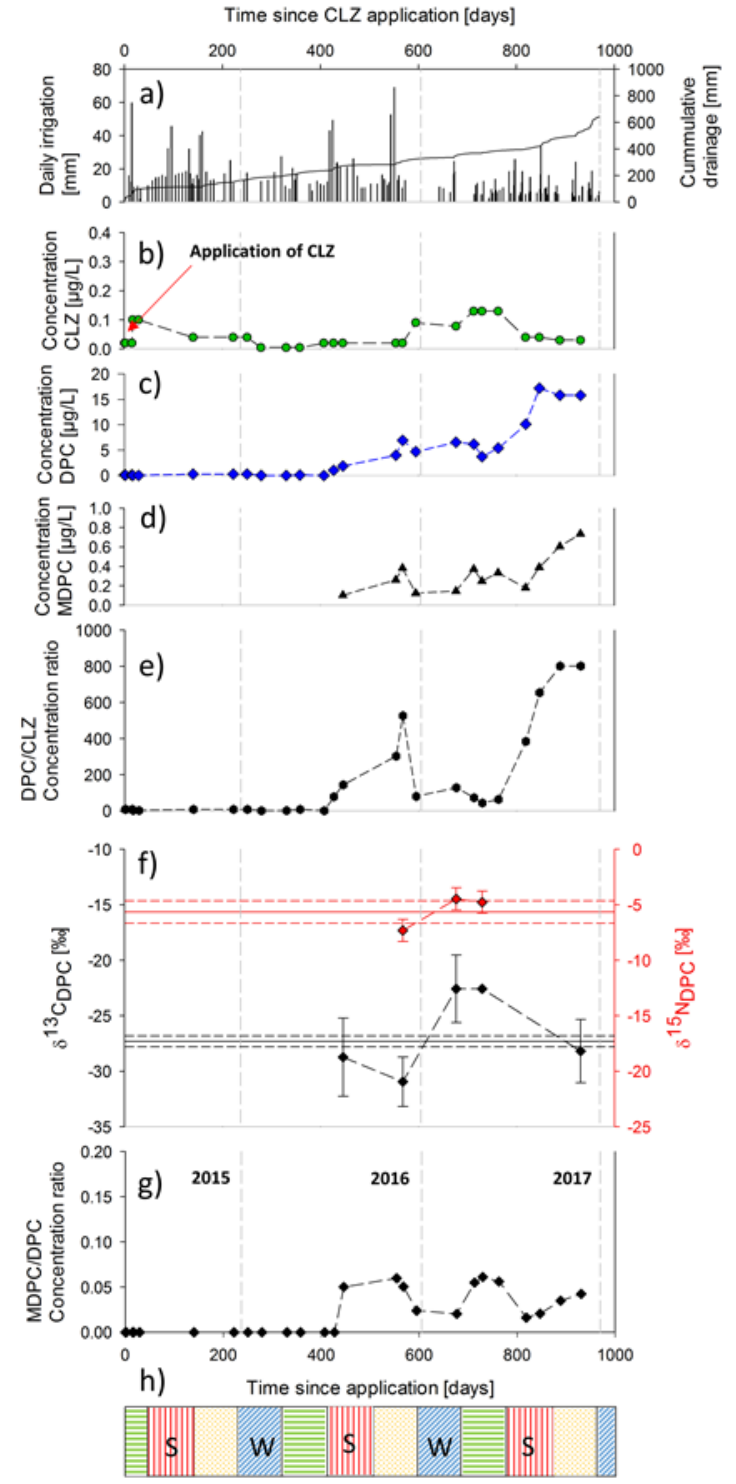

L8, moraine soil
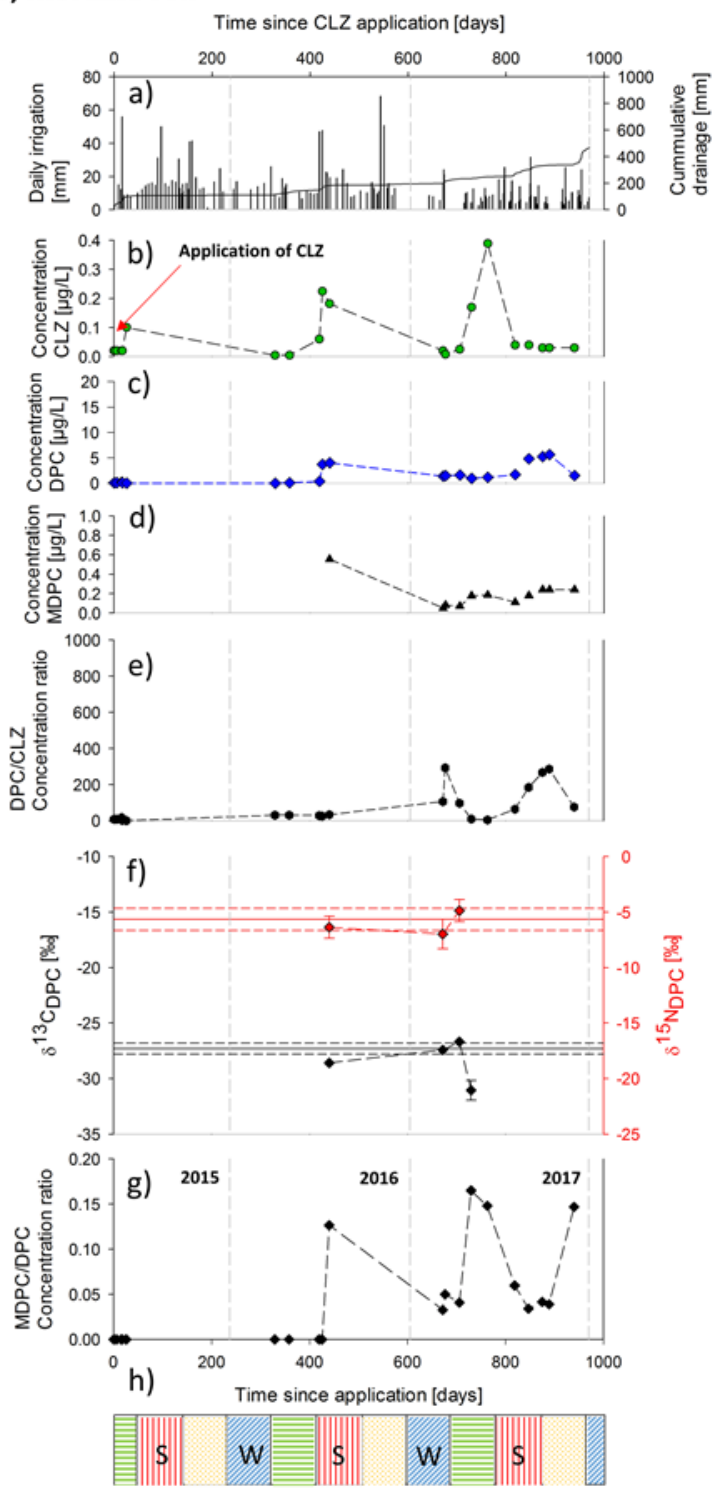

Figure 2. Lysimeters with CLZ application on surface (a single application in May 2015), L4 (left panels) and L8 (right panels). a) Daily irrigation (black bars) and cumulative drainage (grey line), b)-d) Concentration of CLZ (green circles), DPC (blue diamonds) and MDPC (black triangles) over time, e) metabolite-to-parent compound molar ratio of DPC/CLZ (black hexagon), f) carbon (black diamonds) and nitrogen (red diamonds) isotope ratios of DPC, error bars show the associated uncertainties ( $\pm 0.5 \%$ for carbon, $\pm 1.0 \%$ for nitrogen isotope analysis; or when exceeding this uncertainty, standard deviations of triplicate measurements are given, EA isotope values of the applied CLZ are shown as lines, whereas associated uncertainties $( \pm 0.5 \%$ for carbon, $\pm 1.0 \%$ o for nitrogen isotope analysis) are shown as dashed lines in the corresponding color, respectively; $g$ ) metabolite-to-parent compound molar ratio of MDPC/DPC (black diamonds), h) season corresponding to the time since application - spring (green horizontal lines), summer (red vertical lines), autumn (yellow dots), winter (blue diagonal lines); the grey dashed lines repeated in each sub-figure represent the start of a new year. 
In lysimeters with CLZ surface application (Figure 2, L4f and L8f), some carbon isotope values of DPC show a shift to more negative $\delta^{13} \mathrm{C}$ values compared to the carbon isotope signature of the applied CLZ (Table S4). This behavior is observable in both lysimeters, especially after heavy rain events such as that one performed 550 days after CLZ application (November 2016, Table S2), which resulted in a depletion in ${ }^{13} \mathrm{C}$ by $3.4 \%$ for gravel soil (L4). This shift may be attributed to the mobilization of freshly formed DPC, which

412 is formed from CLZ by loss of the aromatic moiety through $\mathrm{C}-\mathrm{N}$ bond cleavage. Presuming that the phenylring contains more ${ }^{13} \mathrm{C}$ atoms than the average molecule (Figure S1), which may have been introduced by 414 the synthesis process, this would result on a ${ }^{13} \mathrm{C}$-depletion. Alternatively, the shift may be due to secondary normal carbon isotope effects. Once transformation of DPC starts - as evidenced by the detection of MDPC - this ${ }^{13} \mathrm{C}$-depletion may be masked compared to the carbon isotope composition of the applied CLZ, as an enrichment in ${ }^{13} \mathrm{C}$ in DPC is expected. Consistently, observed $\delta^{13} C_{D P C}$ values are close to or higher than the EA-IRMS value of the applied CLZ.

In moraine soil (L8), no evidence of DPC degradation was obtained based on carbon isotope values, as changes of $\delta^{13} \mathrm{C}$ values were within the uncertainty of the method (Figure 2, L8f). In contrast, carbon isotope values of DPC in gravel soil (L4) showed an enrichment in ${ }^{13} \mathrm{C}$ by up to $+8.4 \%$ (Figure 2, L4f) indicating that DPC was further transformed. At a subsequent time point (930 days after application), however, the $\delta^{13} C_{D P C}$ value changed back close to the original isotopic signature detected at the beginning of monitoring. This indicates that the change in $\delta^{13} \mathrm{C}$ DPC values was "diluted" by the input of newly mobilized DPC, as supported by a concomitant increase of the DPC/CLZ concentration ratio (Figure 2, L4e). Hence, the two lines of evidence (isotope and DPC/CLZ concentration ratios) were found to complement each other in the assessment of DPC degradation - when one line of evidence was about to fail, the other was able to provide conclusive evidence.

The more substantial changes in both $\delta^{13} C_{D P C}$ values and DPC/CLZ concentration ratios indicate that DPC degradation was higher in L4 (gravel soil) than in L8 (moraine soil) leading to the hypothesis that differences in the transformation rate of CLZ to DPC existed. This is supported by the findings of Capri et al. ${ }^{47}$, who reported that the extent of CLZ degradation is influenced by the moisture content of the soil. As described by Torrentó et al. ${ }^{37}$, there is a higher soil water content and less fluctuation of the water content in the gravel soil than in moraine soil. On the other hand, for both moraine and gravel soil, $\delta^{15} \mathrm{~N}$ values of the DPC formed are, as hypothesized in Figure S1, close to the nitrogen isotope signature of the applied CLZ. Based on the findings of Lingens et al. ${ }^{20}$, the pyridazinone-ring of the CLZ molecule is not 
significant nitrogen isotope fractionation is expected during CLZ transformation to DPC $27,29,48,49$. As the isotope effect during multi-step reactions is reflected by the rate-limiting steps, our results indicate that the amidase-driven cleavage of the moiety (2-hydroxymuconate) at the $\mathrm{C}-\mathrm{N}$ bond, may be not ratelimiting. As a result, changes in nitrogen isotope values of DPC can be uniquely attributed to its further degradation.

Transformation-Potential after Herbicide Injection Below the Root Zone. Finally, two lysimeters (L6 and L7) were chosen to simulate the preferential flow after a heavy irrigation event by injecting CLZ into a depth of $40 \mathrm{~cm}$, following the approach described by Torrentó et al. ${ }^{37}$. In contrast to surface application observations, CLZ and DPC broke through a few days after CLZ was injected (Figure S6). The second metabolite MDPC was detected in the drainage water after 130 days. The detection of the metabolites indicated that CLZ degradation occurred, even when it was injected below the root zone. Additionally, significantly greater concentrations of CLZ, DPC and MDPC (1 to 2 orders of magnitude higher) were measured in the drainage water of the lysimeter with CLZ depth injection compared to the CLZ surface applications. In contrast to surface application observations, early breakthrough of injected uranine and CLZ occurred for the two soil types within a few days ( $<11$ days for gravel and 6 hours for moraine soil) and after a small amount of accumulated drainage ( $<55 \mathrm{~mm}$ and $8 \mathrm{~mm}$, respectively). This rapid response and the peak tailing for both solutes are typical for preferential flow. More than $80 \%$ of the total uranine recovered mass was received during this early breakthrough. These results confirm that preferential flow was enhanced by depth injection. In agreement with Torrentó et al. ${ }^{37}$, the response to intense irrigation events was more significant than for surface applications. It results in several fluctuations of CLZ and DPC concentrations in the drainage water during the first 370 days for both soils (Figure S4). A great increase in CLZ and DPC concentrations occurred in both lysimeters after 330-345 days (at 225-320 mm of accumulated drainage), coinciding with the heavy irrigation events in May 2015 (Table S2). After this pulse, no CLZ was recovered, while a steady increment in accumulated mass recovery was observed for DPC for both soils (Figure S5).

At the end of the monitoring period (1250 days after CLZ injection), total leached analytes accounted for 24 and $22 \%$ of the injected CLZ mass, respectively. Even though comparison between the two application methods may be limited (eleven uniformly distributed CLZ injections versus broad surface application), higher recoveries were obtained for CLZ injection after the same time of monitoring (950 days): from 2.0 to $3.4 \%$ of CLZ, between 16.4 and $17.2 \%$ of DPC and from 0.2 to $0.4 \%$ of MDPC compared to no CLZ 
leaching, 0.13 to $0.15 \%$ of DCP and below $0.02 \%$ of MDPC with surface application. As the mass balance 470 remains incomplete for CLZ injection, there is evidence that additional processes occurred. With surface 471 application, processes such as volatilization ${ }^{46}$, additional transformation pathways ${ }^{19}$ and uptake by 472 plants ${ }^{42}$ likely accounted for the mass losses. Additional influences on the low recovery, which might also 473 occur after CLZ depth injection, might be the low mobility for $\mathrm{CLZ}^{50}$ and the formation of putative fulvic 474 acid complexes of DPC ${ }^{44}$. The DPC/CLZ concentration ratio in these lysimeters with CLZ depth injection 475 shows that the main fraction of DPC seems not to be involved in sorption as this concentration ratio has 476 a single global maximum starting approximately 600 days after CLZ injection (Figure S6). This global 477 concentration maximum is two orders of magnitude greater than DPC/CLZ concentration ratios observed 478 for CLZ surface application. It shows the importance of the topsoil to retain DPC. As indicated by the $479 \mathrm{MDPC} / \mathrm{DPC}$ concentration ratio, further transformation of DPC occurred, although its extent and nature 480 is unknown

481 ANOVA tests were performed to assess the differences between the two soil types and the CLZ application 482 method (i.e. surface application vs. depth injection) regarding DPC leaching and its carbon and nitrogen 483 isotope fractionation. The results showed that the DPC mass leached after 900 days was significantly 484 influenced by the CLZ application method ( $p<0.0001$ ). A 90- to 260 -fold increase in DPC leaching was 485 observed for depth injection compared to surface application. Although the effect of soil type was not statistically significant $(p=0.998)$, CLZ surface application resulted in higher DPC mass leached for gravel than for moraine soil.

488

Similar to observations in lysimeters with CLZ surface application, carbon isotope data of DPC show an enrichment in $\delta^{13} \mathrm{C}$ of $3.8 \%$ after 648 days of herbicide injection below the root zone in the gravel soil, while no significant change is observed in moraine soil (Figure S6). There, up to 648 days, no significant changes in ${ }^{13} \mathrm{C} /{ }^{12} \mathrm{C}$ and ${ }^{15} \mathrm{~N} /{ }^{14} \mathrm{~N}$ ratios were measured. The $\delta{ }^{15} \mathrm{~N}$ value of DPC shows the initial isotope composition of the CLZ applied to the lysimeter. In very few cases, it was possible to measure $\delta^{15} \mathrm{~N}$ values of MDPC formed from DPC (Figure S6 and Table S11). Nitrogen isotope values of MDPC were by approximately $6 \%$ more negative than $\delta^{15} \mathrm{~N}$ signature of its parent compound DPC. This shift agrees with the findings in DPC transformation experiments (Figure 1, L1 and L12) and, thus, supports the nitrogen isotope effect of DPC methylation of approximately $+12 \%$ as estimated above (Table S9 and S10). According to the ANOVA results, isotope fractionation was mainly influenced by the soil type (higher ${ }^{13} \mathrm{C}$ and ${ }^{15} \mathrm{~N}$ enrichment for gravel soil) rather than by the CLZ application method. 

for an overview of observed trends in carbon and nitrogen isotope signatures of DPC (i) either from formation from CLZ, or (ii) when DPC was further transformed. In Figure 3a, isotope data of all lysimeters with DPC surface application are combined, whereas in Figure $3 b$, data of all lysimeters with CLZ application/injection are shown. In Figure 3a, where DPC represents the original applied compound, a general trend towards more positive $\delta^{15} \mathrm{~N}$ and $\delta^{13} \mathrm{C}$ values is observable. This observation is consistent with the well-established phenomenon that, in most cases, heavy isotopes become enriched in the remaining substrate during (bio)degradation. As detailed above, DPC in first drainage samples (first 450 days) of the gravel soil showed a significant enrichment in ${ }^{13} \mathrm{C}$ but not in ${ }^{15} \mathrm{~N}$, indicating that two distinct processes for DPC transformation occurred. In contrast, Figure $3 \mathrm{~b}$ shows two opposing trends pointing to the occurrence of both DPC formation and transformation. On the one hand, similar to the lysimeters with DPC application, a trend is observed towards more positive $\delta^{13} \mathrm{C}$ and $\delta^{15} \mathrm{~N}$ values during the transformation of DPC. On the other hand, numerous data points show more negative $\delta^{13} \mathrm{C}$ and $\delta^{15} \mathrm{~N}$ isotope values. As this trend is only observable for lysimeters with CLZ application and injection, we attribute it to the formation of DPC. As discussed above, possible explanations for the observed depletion in ${ }^{13} \mathrm{C}$ (more negative $\delta^{13} \mathrm{C}$ values) is (i) an artefact of an uneven ${ }^{13} \mathrm{C}$ isotope distribution in the cleaved phenyl-ring during DPC formation; or (ii) that the formation of DPC from CLZ (Figure S1) may be accompanied by a small and normal secondary carbon isotope effect.

\section{a) DPC Surface Application}

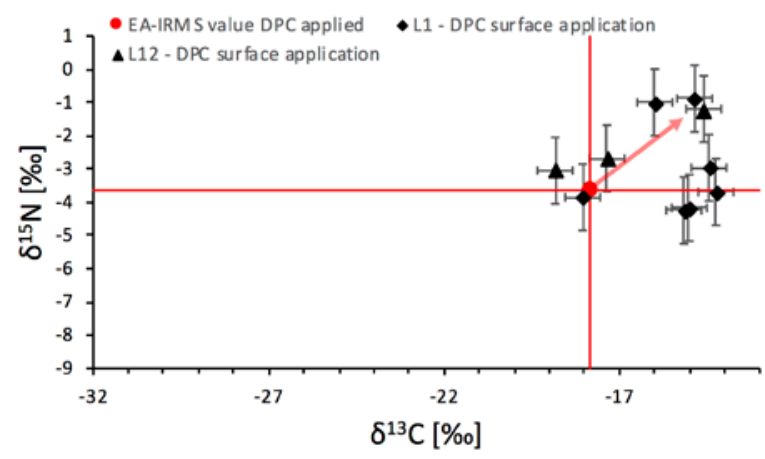

b) Chloridazon Application / Injection

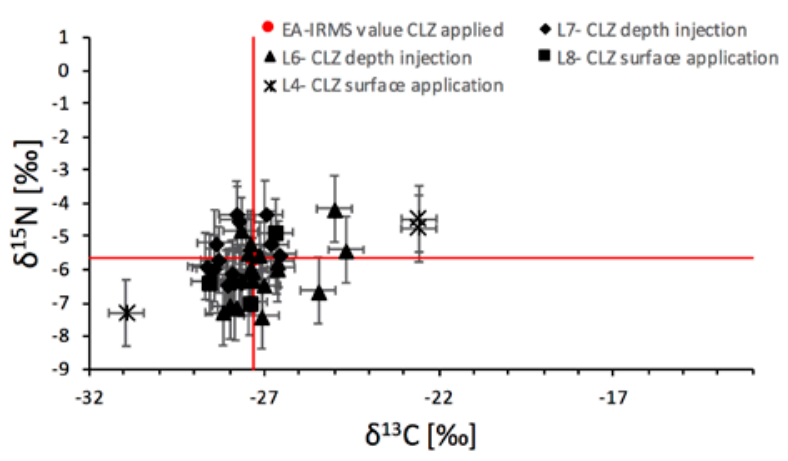

518

Figure 3. Dual-element isotope plot of a) DPC degradation in lysimeters L1 and L12, where DPC was applied on the surface, and b) formation and degradation of DPC in the lysimeters where CLZ was either applied (L4 and L8) or injected in a depth of $40 \mathrm{~cm}$ (L6 and L7); the red circles represent the isotopic signature of the applied/injected a) DPC and b) CLZ - position of CLZ and DPC differ within the dual-element isotope plots due to their different isotopic source signatures (Table S4). 


\section{Environmental Significance and Outlook}

525 The isotope fractionation in DPC observed for the three tested scenarios is particularly important because

526 (i) the change in carbon and nitrogen isotopic signature of DPC evidenced transformation of an apparently

527 persistent metabolite, and (ii) these changes provide evidence that likely more than one transformation

528 pathway is involved in DPC transformation. In soil, only methylation of DPC to MDPC is known and thus

529 our data suggest the need for further laboratory experiments and mechanistic studies on DPC

530 (bio)degradation to gain further insight into possible additional transformation pathways. (iii) Formed

531 DPC, which had not been subject to further transformation yet, showed the same nitrogen isotope

532 signature as its precursor CLZ. Hence, $\delta^{15} \mathrm{~N}$ values may serve as isotopic fingerprints to identify the origin

533 of such compounds in groundwater.

534 When applying CSIA, the combination with conventional methods was found to be complementary and 535 advantageous, especially when formation and transformation of the metabolite was occurring 536 simultaneously. Once introduction of newly formed metabolite dominated, evidence from CSIA was not necessarily conclusive because transformation-related changes in isotope ratios were masked by the continuous input of DPC. Here, additional information was gained by metabolite-to-parent concentration ratios, which became greatest and could provide evidence of DPC formation. Vice versa, when metabolite-

540 to-parent-ratios were small because DPC was further transformed, it was the changes in isotope ratios of

541 DPC which still carried the isotopic imprint of the reaction and, hence, made transformation visible. For 542 further understanding of the environmental fate of DPC, reference experiments focusing on the 543 determination of stable isotope fractionation factors as well as microbial processes during DPC 544 transformation are required in order to identify transformation mechanisms and quantify them.

545 For the future, our approach with CSIA in combination with concentration measurements and systematic 546 long-term lysimeter experiments holds promise to answer questions about transformation pathways and 547 the extent of soil / vadose zone (bio)transformation not only for DPC - one of the most widely detected 548 substances - in groundwater, but also for other micropollutants of concern and their metabolites. 549 Additionally, this study confirmed that the application of CSIA in combination with solid-phase 550 extraction ${ }^{27,39}$ is feasible for the analysis of polar micropollutants in drainage water at environmentally 551 relevant concentrations. Thus, it can be also applied to studies in agricultural soil and groundwater from 552 common unconsolidated sand and/or gravel aquifers with catchment areas within agricultural production. 
555 Further details on chemicals, lysimeters, analytical methods, analyte recovery calculations and results of 556 water balance computation, vegetation cover evolution, breakthrough trends, EA-IRMS analyses, soil 557 analyses, CLZ depth injection and nitrogen isotope ratios.

558

559 AUTHOR INFORMATION

560 Corresponding Author

561 *Phone: + 49892180 78232; fax: + 49892180 78255; e-mail: m.elsner@tum.de

562

563 Author Contributions

$564 \quad$ TThese authors contributed equally as first authors to this work.

565 Present Addresses

$566{ }^{\S}$ Technical University of Munich, Chair of Analytical Chemistry and Water Chemistry, 81377 Munich, 567 Germany.

568 TGrup MAiMA, Departament de Mineralogia, Petrologia i Geologia Aplicada, Facultat de Ciències de la 569 Terra, Universitat de Barcelona (UB), C/ Martí i Franquès s/n, 08028, Barcelona, Spain.

570 'Département des sciences de la Terre et de l'atmosphère, Université du Québec à Montréal, 201 avenue 571 du Président Kennedy, Montréal, QC, Canada.

\section{$572 \quad$ Notes}

573 The authors declare no competing financial interest.

\section{ACKNOWLEDGMENT}

575 This study was supported by the project CRSII2_141805/1 from the Swiss National Science Foundation 576 (SNSF). The authors would like to thank the NPAC (UNiNE) and Jakov Bolotin (Eawag) for their help in the 577 laboratory as well as Doris Ebert from BASF for providing the chemical DPC.

578

579 ABBREVIATIONS

580 CLZ - 5-Amino-4-chloro-2-phenyl-2H-pyridazin-3-one

581 DPC - 5-Amino-4-chloro-3(2H)-pyridazinone

582 MDPC - 5-Amino-4-chloro-2-methyl-3(2H)-pyridazinone 


\section{References}

1. EuropeanCommission, Groundwater Protection in Europe The new Groundwater Directive: consolidating the EU regulatory framework In European Commission-Directorate-General for Environment, EU Publications: Brussels, 2008.

2. BAFU, B. f. U., Pflanzenschutzmittel PSM und PSM-Abbauprodukte im Grundwasser. In NAQUA, N. G., Ed. Switzerland, 2013.

3. Loos, R.; Gawlik, B. M.; Locoro, G.; Rimaviciute, E.; Contini, S.; Bidoglio, G., EU-wide survey of polar organic persistent pollutants in European river waters. Environ. Pollut. 2009, 157, (2), 561-568. 4. Reemtsma, T.; Alder, L.; Banasiak, U., A multimethod for the determination of 150 pesticide metabolites in surface water and groundwater using direct injection liquid chromatography-mass spectrometry. J. Chromatogr. A 2013, 1271, (1), 95-104.

5. Postigo, C.; Barceló, D., Synthetic organic compounds and their transformation products in groundwater: Occurrence, fate and mitigation. Sci. Total Environ. 2015, 503-504, 32-47.

6. Fenner, K.; Canonica, S.; Wackett, L. P.; Elsner, M., Evaluating Pesticide Degradation in the Environment: Blind Spots and Emerging Opportunities. Science 2013, 341, (6147), 752-758.

7. Thier, H.-P.; Zeumer, H., Manual of Pesticide Residue Analysis Volume I. VCH Verlagsgesellschaft: 1987; p 443.

8. $\quad$ Drescher, N.; Otto, S., Über den Abbau von 1-Pheny1-4-amino-5-chlor-pyridazon-6 (Pyrazon) im Boden Zeitschrift für Pflanzenkrankheiten (Pflanzenpathologie) und Pflanzenschutz 1969, 76, (1), 27-33. 9. Hertfordshire, U. O., PPDB: Pesticide Properties DataBase. In University of Hertfordshire: http://sitem.herts.ac.uk/aeru/ppdb/en/Reports/141.htm, 2018.

10. Buttiglieri, G.; Peschka, M.; Frömel, T.; Müller, J.; Malpei, F.; Seel, P.; Knepper, T. P., Environmental occurrence and degradation of the herbicide n-chloridazon. Water Res. 2009, 43, (11), 2865-2873.

11. Loos, R.; Locoro, G.; Comero, S.; Contini, S.; Schwesig, D.; Werres, F.; Balsaa, P.; Gans, O.; Weiss, S.; Blaha, L.; Bolchi, M.; Gawlik, B. M., Pan-European survey on the occurrence of selected polar organic persistent pollutants in ground water. Water Res. 2010, 44, (14), 4115-4126.

12. Weber, W. H.; Seitz, W.; Schulz, W.; Wagener, H.-A., Nachweis der Metaboliten Desphenylchloridazon und Methyl-desphenyl-chloridazon in Oberflächen, Grund- und Trinkwasser. Vom Wasser 2007, 105 (1), 7-14.

13. Reinhardt, M. K., Ronald; Hofacker, Anke; Leu, Christian Monitoring von PSM-Rückständen im Grundwasser. Aqua Gas 2017, 6, 78-89.

14. Sturm, S.; Kiefer, J.; Kollotzek, D.; Rogg, J.-m., Aktuelle Befunde der Metaboliten von Tolylfluanid und Chloridazon in den zur Trinkwasserversorgung genutzten Grundwasservorkommen BadenWürttembergs. gwf Wasser / Abwasser 2013, (10), 950-959\%V 151.

15. Deutsche-Forschungsgemeinschaft, Rückstandsanalytik von Pflanzenschutzmitteln", Mitteilung VI der Senatskommission für Pflanzenschutz-, Pflanzenbehandlungs- und Vorratsschutzmittel, Methodensammlung der Arbeitsgruppe Analytik, 11. Wiley VCH: 1990.

16. Gustafson, D. I., Groundwater ubiquity score: A simple method for assessing pesticide leachability. Environmental Toxicology and Chemistry 1989, 8, (4), 339-357.

17. Grummt, T. P., Rudolf, Gesundheitliche Orientierungswerte (GOW) für nicht relevante Metaboliten (nrM) von Wirkstoffen aus Pflanzenschutzmitteln (PSM). In Risikobewertung, U. a. B. f., Ed. Umweltbundesamt and Bundesinstitut für Risikobewertung: https://www.umweltbundesamt.de/dokument/gesundheitliche-orientierungswerte-gow-fuer-nicht, 2017; $p 12$.

18. UBA, Pflanzenschutzmittelfunde im Grundwasser. In Umweltbundesamt: 2004. 
19. Roberts, M. C.; Croucher, L.; Roberts, T. R.; Hutson, D. H.; Lee, P. W.; Nicholls, P. H.; Plimmer, J. R., Metabolic Pathways of Agrochemicals: Part 1: Herbicides and Plant Growth Regulators. Royal Society of Chemistry: 2007. 20. Lingens, F.; Blecher, R.; Blecher, H.; Blobel, F.; Eberspächer, J.; Fröhner, C.; Görisch, H.; Görisch, H.; Layh, G., Phenylobacterium immobile gen. nov., sp. nov., a Gram-Negative Bacterium That Degrades the Herbicide Chloridazon. Int. J. Syst. Evol. Microbiol. 1985, 35, (1), 26-39.

21. Farlin, J.; Bayerle, M.; Pittois, D.; Gallé, T., Estimating Pesticide Attenuation From Water Dating and the Ratio of Metabolite to Parent Compound. Groundwater 2017, 55, (4), 550-557.

22. Meyer, A. H.; Elsner, M., $13 \mathrm{C} / 12 \mathrm{C}$ and $15 \mathrm{~N} / 14 \mathrm{~N}$ Isotope Analysis To Characterize Degradation of Atrazine: Evidence from Parent and Daughter Compound Values. Environ. Sci. Technol. 2013, 47, (13), 6884-6891.

23. Hunkeler, D.; Meckenstock, R. U.; Sherwood Lollar, B.; Schmidt, T.; Wilson, J.; Schmidt, T.; Wilson, J. A Guide for Assessing Biodegradation and Source Identification of Organic Ground Water Contaminants using Compound Specific Isotope Analysis (CSIA); PA 600/R-08/148 | December 2008 | www.epa.gov/ada; US EPA: Oklahoma, USA, 2008.

24. Thullner, M.; Richnow, H.-H.; Fischer, A., Characterization and quantification of in situ biodegradation of groundwater contaminants using stable isotope fractionation analysis: advantages and limitations. In Environmental and Regional Air Pollution, Gallo, D.; Mancini, R., Eds. Nova Science Publishers: 2009.

25. Meckenstock, R. U.; Morasch, B.; Griebler, C.; Richnow, H. H., Stable isotope fractionation analysis as a tool to monitor biodegradation in contaminated acquifers. Journal of Contaminant Hydrology 2004, 75, (3-4), 215-255.

26. Alvarez-Zaldívar, P.; Payraudeau, S.; Meite, F.; Masbou, J.; Imfeld, G., Pesticide degradation and export losses at the catchment scale: Insights from compound-specific isotope analysis (CSIA). Water Res. 2018, 139, 198-207.

27. Melsbach, A.; Ponsin, V.; Torrentó, C.; Lihl, C.; Hofstetter, T. B.; Hunkeler, D.; Elsner, M., $13 C$ and $15 \mathrm{~N}$ isotope analysis of desphenylchloridazon by liquid chromatography isotope ratio mass spectrometry (LC-IRMS) and derivatization-gas chromatography isotope ratio mass spectrometry (GCIRMS). Anal. Chem. 2019, 91, (5), 3412-3420.

28. Elsner, M., Stable isotope fractionation to investigate natural transformation mechanisms of organic contaminants: principles, prospects and limitations. J. Environ. Monit. 2010, 12, (11), 2005-2031. 29. Muller, R.; Schmitt, S.; Lingens, F., A novel non-heme iron-containing dioxygenase. Chloridazoncatechol dioxygenase from Phenylobacterium immobilis DSM 1986. European journal of biochemistry / FEBS 1982, 125, (3), 579-84.

30. Braeckevelt, M.; Fischer, A.; KÃßstner, M., Field applicability of Compound-Specific Isotope Analysis (CSIA) for characterization and quantification of in situ contaminant degradation in aquifers. Appl. Microbiol. Biotechnol. 2012, 94, (6), 1401-1421.

31. Kopinke, F. D.; Georgi, A.; Voskamp, M.; Richnow, H. H., Carbon isotope fractionation of organic contaminants due to retardation on humic substances: Implications for natural attenuation studies in aquifers. Environ. Sci. Technol. 2005, 39, (16), 6052-6062.

32. Fischer, A.; Theuerkorn, K.; Stelzer, N.; Gehre, M.; Thullner, M.; Richnow, H. H., Applicability of Stable Isotope Fractionation Analysis for the Characterization of Benzene Biodegradation in a BTEXcontaminated Aquifer. Environ. Sci. Technol. 2007, 41, (10), 3689-3696.

33. Morrill, P. L.; Sleep, B. E.; Seepersad, D. J.; McMaster, M. L.; Hood, E. D.; LeBron, C.; Major, D. W.; Edwards, E. A.; Sherwood Lollar, B., Variations in expression of carbon isotope fractionation of chlorinated ethenes during biologically enhanced PCE dissolution close to a source zone. Journal of Contaminant Hydrology 2009, 110, (1-2), 60-71. 
34. Stehmeier, L. G.; Francis, M. M.; Jack, T. R.; Diegor, E.; Winsor, L.; Abrajano, T. A., Field and in vitro evidence for in-situ bioremediation using compound-specific $13 \mathrm{C} / 12 \mathrm{C}$ ratio monitoring. Org. Geochem. 1999, 30, (8, Part 1), 821-833.

35. Hunkeler, D.; Aravena, R.; Parker, B. L.; Cherry, J. A.; Diao, X., Monitoring oxidation of chlorinated ethenes by permanganate in groundwater using stable isotopes: laboratory and field studies. Environ. Sci. Technol. 2003, 37, 798-804.

36. Elsner, M.; Lacrampe Couloume, G.; Mancini, S. A.; Burns, L.; Sherwood Lollar, B., Carbon Isotope Analysis to Evaluate Nanoscale Fe(0) Treatment at a Chlorohydrocarbon Contaminated Site. Groundwater Monitoring and Remediation 2010, 30, 79-95.

37. Torrentó, C.; Prasuhn, V.; Spiess, E.; Ponsin, V.; Melsbach, A.; Lihl, C.; Glauser, G.; Hofstetter, T. B.; Elsner, M.; Hunkeler, D., Adsorbing vs. Nonadsorbing Tracers for Assessing Pesticide Transport in Arable Soils. Vadose Zone J. 2018, 17, (1).

38. IUSS_Working_Group_WRB, World Reference Base for Soil Resources 2014, update 2015 International soil classification system for naming soils and creating legends for soil maps. . Food and Agriculture Organization of the United Nations: Rome, 2015; Vol. 106.

39. Torrentó, C.; Bakkour, R.; Gaétan, G.; Melsbach, A.; Ponsin, V.; Hofstetter, T. B.; Elsner, M.; Hunkeler, D., Solid-phase extraction method for stable isotope analysis of pesticides from large volume environmental water samples. Analyst 2019, 144, (9), 2898-2908

40. Meyer, A. H.; Penning, H.; Lowag, H.; Elsner, M., Precise and accurate compound specific carbon and nitrogen isotope analysis of atrazine: critical role of combustion oven conditions. Environ. Sci. Technol. 2008, 42, (21), 7757-7763.

41. Werner, R. A.; Brand, W. A., Referencing strategies and techniques in stable isotope ratio analysis. Rapid Commun. Mass Spectrom. 2001, 15, 501-519.

42. Schuhmann, A.; Gans, O.; Weiss, S.; Fank, J.; Klammler, G.; Haberhauer, G.; Gerzabek, M., A longterm lysimeter experiment to investigate the environmental dispersion of the herbicide chloridazon and its metabolites-comparison of lysimeter types. J. Soils Sediments 2016, 16, (3), 1032-1045.

43. Stephenson, G. R.; Ries, S. K., Metabolism of Pyrazon in Sugar Beets and Soil. Weed Science 1969, 17, (3), 327-331.

44. Gatzweiler, E., Das Langzeitverhalten der Herbizidwirkstoffe Chloridazon und 2, 4-DP-P nach Praxisanwendung in zwei verschiedenen Boden der Bundesrepublik. 1993.

45. PESTEMER, W.; MALKOMES, H.-P., Einfluss von Pflanzenschutzmitteln einer ZuckerrübenSpritzfolge auf biologische Aktivitäben und auf den Abbau von Chloridazon im Boden. I. Freilandversuche. Weed Res. 1983, 23, (5), 283-291.

46. Barra, R.; Vighi, M.; Di Guardo, A., Prediction of surface water input of chloridazon and chlorpyrifos from an agricultural watershed in Chile. Chemosphere 1995, 30, (3), 485-500.

47. Capri, E.; Ghebbioni, C.; Trevisan, M., Metamitron and Chloridazon Dissipation in a Silty Clay Loam Soil. J. Agric. Food Chem. 1995, 43, (1), 247-253.

48. Elsner, M.; Zwank, L.; Hunkeler, D.; Schwarzenbach, R. P., A new concept linking observable stable isotope fractionation to transformation pathways of organic pollutants. Environ. Sci. Technol. 2005, 39, (18), 6896-6916.

49. Elsner, M.; Jochmann, M. A.; Hofstetter, T. B.; Hunkeler, D.; Bernstein, A.; Schmidt, T. C.; Schimmelmann, A., Current challenges in compound-specific stable isotope analysis of environmental organic contaminants. Anal. Bioanal. Chem. 2012, 403, (9), 2471-2491.

50. DE FANG, F.; PESTEMER, W.; MALKOMES, H.-P., Einfluss von Pflanzenschutzmitteln einer Zuckerrüben-Spritzfolge auf biologische Aktivitäten und auf den Abbau von Chloridazon im Boden. II. Gefäss-und Laborversuche. Weed Res. 1983, 23, (5), 293-304. 